\title{
An in vitro Analysis of Sound Localization Mechanisms in the Gerbil Lateral Superior Olive
}

\author{
Dan H. Sanes \\ Departments of Otolaryngology, and Physiology and Biophysics, New York University Medical Center, New York, \\ New York 10016
}

One way in which animals localize sounds along the horizon is by detecting the level differences at the 2 ears. Neurons in the lateral superior olive (LSO) encode this cue by integrating the synaptic drive from ipsilateral excitatory and contralateral inhibitory connections. This synaptic integration was analyzed in $400-500-\mu \mathrm{m}$ brain slices through the gerbil superior olive. Intracellular recordings from LSO neurons were obtained during the application of independent or conjoint electrical stimuli to the excitatory afferent and inhibitory afferent pathways. Stimulation of ascending fibers from the ipsilateral cochlear nucleus reliably evoked EPSPs and action potentials. Stimulation of the medial nucleus of the trapezoid body (MNTB) consistently evoked IPSPs. The evoked postsynaptic potentials differed in that IPSPs were 2 times the duration of EPSPs. An electrophysiological estimate of convergence indicated approximately 10 excitatory and 8 inhibitory afferents per LSO neuron. MNTB stimulation suppressed synaptically evoked action potentials. When stimulus amplitude was Increased to the excitatory pathway, it was generally found that a greater MNTB stimulus was necessary to suppress the action potential. A similar commensurate rise in ipsilateral and contralateral acoustic stimulation was also found to be necessary to give the same criterion response. These results confirm that the LSO can integrate evoked action potentials and IPSPs to encode interaural level. Increasing stimulus voltage was found to decrease both action potential and IPSP latency, suggesting that intensity information may be encoded with temporal cues in the nervous system. It was also found that an evoked burst of action potentials could be inhibited in such a way as to yield intermediate discharge rates, dependent on contralateral stimulus level. Taken together, these results suggest that certain properties related to level-difference coding may be available for intracellular analysis using the brain-slice preparation. Several temporal characteristics of the synaptic potentials, including latency and duration, may play a critical role in this simple computation.

\footnotetext{
Received Mar. 21, 1990; revised June 6, 1990; accepted June 6, 1990.

I wish to thank Mr. Frank Liou for expert design of the software for acquisition and analysis of the data, Dr. Robert Baker for valuable discussions, Dr. Christopher Leonard for technical advice, Ms. Veronica Siverls for technical assistance and Drs. Noel L. Cohen and Rodolfo Llinas for providing an extremely supportive environment. The in vivo single-neuron recordings were obtained in Dr. E. W. Rubel's laboratory, then at the University of Virginia Medical Center. This work was supported in part by the Mendik Research Fund, a Whitehead Fellowship, and NIH grant 1R29 DC00540-01A1. D.H.S. is a Sloan Foundation Fellow.

Correspondence should be addressed to Dan H. Sanes, Department of Physiology and Biophysics, New York University School of Medicine, 550 First Avenue, New York, NY 10016.

Copyright (C) 1990 Society for Neuroscience $0270-6474 / 90 / 113494-13 \$ 03.00 / 0$
}

One of the fundamental ways that animals are able to localize sound stimuli in the horizontal plane is by computing the level difference between 2 ears. This perceptual task is ideal for neurophysiological analyses because a great deal of information is now available about the psychophysical and cellular correlates of sound localization. However, the underlying synaptic mechanisms have yet to be examined in any detail. With the advent of the brain-slice preparation, it is now possible to extract the key elements of the auditory pathway that first compute binaural sound-level differences and to explore the synaptic and ionic mechanisms.

Psychophysical and acoustical analyses have determined that 2 principal cues are used by mammals when determining azimuthal location: interaural time differences and interaural level differences (Rayleigh, 1945; Feddersen et al., 1957; Mills, 1958; Durlach and Colburn, 1978). For high-frequency stimuli, a sound's position may be predicted by the difference in sound level at each ear. The general clarity of this psychophysical data has led to many studies of related central auditory coding properties (Rose et al., 1966; Brugge et al., 1969, 1970; Goldberg and Brown, 1969; Harnischfeger et al., 1985; Fuzessery and Pollak, 1985; Wenstrup et al., 1986; Semple and Kitzes, 1987). Recordings from the ventral auditory brain stem, where inputs from the 2 ears first converge, demonstrate that lateral superior olivary (LSO) neurons are predominantly excited by acoustic stimuli presented to the ipsilateral ear and inhibited by contralateral stimulation (Boudreau and Tsuchitani, 1968).

The ipsilateral afferent pathway to the LSO originates in the cochlear nucleus (Warr, 1982; Cant and Casseday, 1986) and is arranged tonotopically. The contralateral pathway differs in that the inhibitory neurons of the medial nucleus of the trapezoidal body (MNTB) are interposed between the cochlear nucleus and the LSO (Rasmussen, 1946; Morest, 1968; Browner and Webster, 1975; Tolbert et al., 1982; Glendenning et al., 1985; Spangler et al., 1985; Zook and DiCaprio, 1988).

LSO neurons are quite sensitive to sound level differences between the 2 ears. The evoked discharge rate of a neuron is a consequence of the difference between ipsilateral excitatory and contralateral inhibitory synaptic drives (Boudreau and Tsuchitani, 1970; Caird and Klinke, 1983; Harnischfeger et al., 1985; Sanes and Rubel, 1988). Neurons in the adult gerbil LSO modulate their discharge rates over a mean level-difference range of $28 \mathrm{~dB}$ and have maximal resolution at distinct interaural level differences (i.e., at distinct azimuthal loci). Behavioral experiments have demonstrated that gerbils can localize sound cues through level differences, with a resolution of not less than $14^{\circ}$ (Heffner and Heffner, 1988).

High-frequency sounds can also be localized using interaural time differences if the signal is modulated at a low frequency 


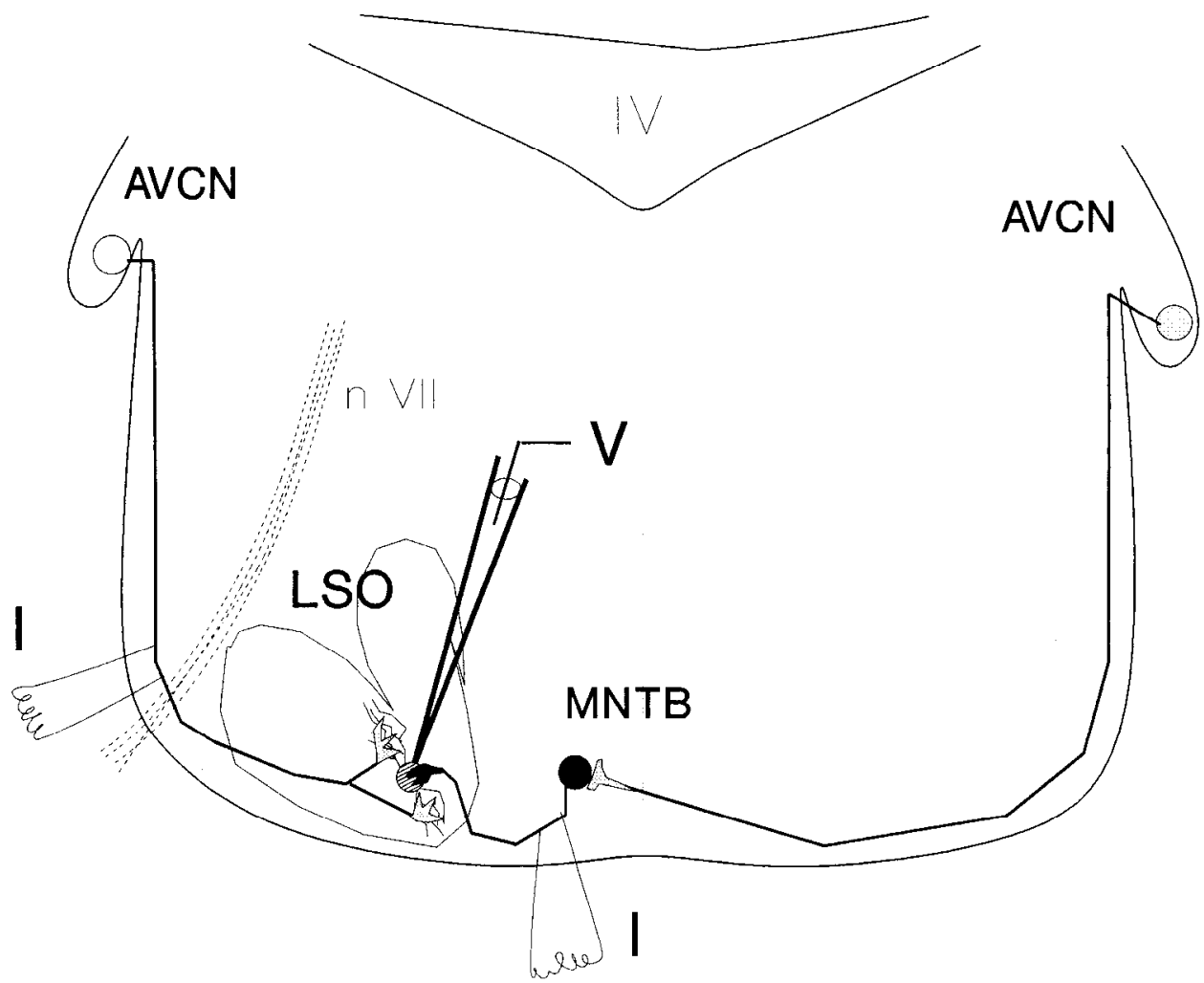

Figure 1. A schematic of gerbil brainslice preparation. The brain stem is sectioned in the transverse plane and contains the lateral superior olive $(L S O)$, the medial nucleus of the trapezoid body $(M N T B)$, and afferent fibers from the ipsilateral anteroventral cochlear nucleus $(A V C N)$. Intracellular recordings $(V)$ were obtained from LSO neurons while electrical stimuli $(I)$ were delivered to afferent pathways from the AVCN and/or the MNTB.

and presented several times (Henning, 1974; McFadden and Pasanen, 1976; Yost, 1976). Therefore, temporal cues may be of general importance to LSO neurons for computing the azimuthal location. In fact, it has been demonstrated in several auditory centers that the response to interaural level differences may be modulated by varying stimulus latency to the 2 ears (Brugge et al., 1969; Kitzes et al., 1980; Caird and Klinke, 1983; Yin et al., 1985; Pollak, 1988). Yin and coworkers (1985) have proposed that there is a common neural mechanism for computations of interaural time and level that involves temporal coincidence of afferent discharge.

The following experiments demonstrate that electrical stimuli delivered to the 2 major afferent pathways to the LSO evoke appropriate synaptic responses. The integration of these synaptic potentials yield response properties that bear some resemblance to those seen in vivo. The amount of convergence onto LSO neurons and several temporal properties of the evoked responses are proposed as contributing to level-difference coding.

\section{Materials and Methods}

Brain-slice preparation. Gerbils (Meriones unguiculatus), aged 17-23 d postnatal, were used to produce brain slices through the ventral auditory brain stem. An animal was decapitated, and the brain was rapidly dissected free in oxygenated artificial cerebrospinal fluid (ACSF: $\mathrm{NaCl}$, $127.4 \mathrm{~mm} ; \mathrm{KCl}, 5 \mathrm{~mm} ; \mathrm{KH}_{2} \mathrm{PO}_{4}, 1.2 \mathrm{~mm} ; \mathrm{MgSO}_{4} \cdot 7 \mathrm{H}_{2} \mathrm{O}, 1.3 \mathrm{~mm}$; $\mathrm{NaHCO}_{3}, 26 \mathrm{~mm}$; glucose, $15 \mathrm{~mm} ; \mathrm{CaCl}_{2} \cdot 2 \mathrm{H}_{2} \mathrm{O}, 2.4 \mathrm{~mm} ; \mathrm{pH}=7.4$ ) at $10-15^{\circ} \mathrm{C}$. The pia mater was removed and the cerebellum trimmed before mounting the brain stem onto a piece of $4 \%$ agar with cyanoacrylate glue. The tissue was then sectioned with a vibratome (TPI Series 1000 ) in ACSF at $400-500 \mu \mathrm{m}$, and the sections were incubated in a holding chamber for $30-45 \mathrm{~min}$.

A tissue slice was placed in the recording chamber (Medical System Instruments) and held in place on a nylon mesh with small platinum pins. The oxygenated ACSF was perfused at a rate of $9 \mathrm{ml} / \mathrm{min}$, and the temperature was gradually increased to $31-32^{\circ} \mathrm{C}$. Two concentric bipolar stimulating electrodes (Rhodes) were lowered to contact the ipsilateral afferent pathway at the level of the facial nerve and the contralateral afferent pathway at the lateral edge of the medial nucleus of the trapezoid body (Figure 1). Electrical stimuli consisted of $100-\mu \mathrm{sec}$ pulses delivered at $0-60 \mathrm{~V}$ through an isolated source (Grass Instruments S11 and SIU5).

Intracellular recording. Electrodes were fabricated (Sutter Instruments) and filled with $2 \mathrm{M}$ potassium citrate to give resistances in the range of 120-180 M . The electrode holder was mounted to a microdrive (Burleigh Inchworm) for stable movement through the tissue in 1 $\mu \mathrm{m}$ steps. Periodic sinusoidal current pulses were applied to facilitate penetration. When a neuron was impaled, as evidenced by a rapid drop in potential across the electrode, stimulus pulses were delivered with the stimulating electrodes to verify that synaptic transmission was present. The criteria for selecting a neuron required that the resting potential be at least $-50 \mathrm{mV}$, that ipsilateral stimuli elicit EPSPs and action potentials, and that contralateral stimuli elicit IPSPs. There were a small number of neurons that were responsive to stimuli from only 1 electrode or were excited by stimuli to either electrode, but such responses could have heen an artifact of cut afferents or stimulus-current spread and are not included in the present analysis. When feasible, $200-\mathrm{msec}$ current pulses were delivered through the electrode, and the voltage across the membrane was monitored. The mean resting potential for all analyzcd neurons was $-54 \mathrm{mV}(N=37)$.

Data acquisition and analysis. The voltage signal was fed from an electrometer (Axon Instruments Axoprobe A-1) to an oscilloscope (Tektronix 5116) and recorded on magnetic tape (Neurocorder DR-384 and Panasonic VHS) for off-line analysis or entered directly into the computer (33 MHz PC-AT with Data Translation $2828 \mathrm{D} / \mathrm{A}$ board) for online analysis. Digital and analog data were analyzed using custom-designed software. The intracellular recordings were digitized with the D/A converter sampling at $10 \mathrm{kHz}$ using an on-board clock reference and were stored along with the relevant stimulus parameters.

Figure 2 shows the hasic analyses that were performed on the evoked synaptic potentials. The acquired synaptic potentials were analyzed for latency by determining the time at which the signal increased above the baseline noise level and the time at which a maximum amplitude was obtained. The duration was determined from the rising latency to the time at which the signal returned to the baseline noise level. The slope was defined as the maximum slope over any $0.5-\mathrm{msec}$ interval before a maximum amplitude was obtained. The area $(\mathrm{mV} \cdot \mathrm{msec})$ between each synaptic potential and baseline was also computed in order to estimate the number of excitatory or inhibitory afferents that innervated each 

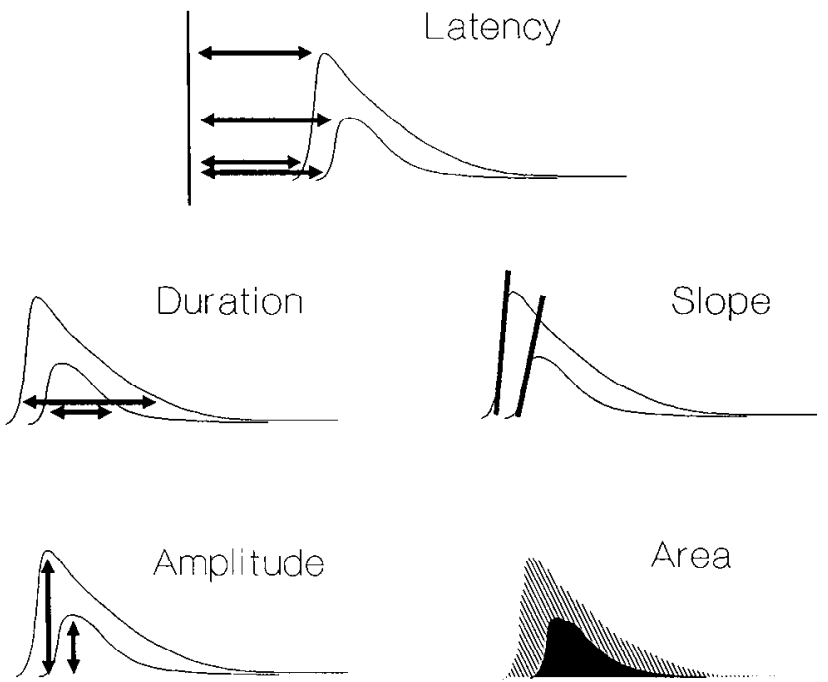

Figure 2. Analyses performed on synaptic potentials. All excitatory and inhibitory synaptic potentials were characterized for maximum and minimum delay to rise and peak (top), maximum and minimum durations (middle left), maximum slope (middle right), maximum and minimum amplitudes (bottom left), and the area $(\mathrm{mV} \cdot \mathrm{msec})$ between potential and baseline (bottom right). The average values are summarized in Table 1.
LSO neuron. The reasoning was as follows: It has commonly been found that stimulus-evoked synaptic potentials appear as quantal increases in amplitude as additional afferents are recruited to discharge (Redfern, 1970; J ichtman, 1977; Mariani and Changeux, 1981; Jackson and Parks, 1982). When there are a relatively large number of afferents present, the quantal increases may be difficult to discriminate from one another. Therefore, integrating each potential should provide a more sensitive estimate of potential size. A computer-directed process discriminated between potential sizes using the expected level of noise from the pretrial interval.

Auditory neurophysiology. The delivery of acoustic stimuli and recording of single neuron response properties have been described in detail previously (Sanes and Rubel, 1988). Adult gerbils, aged 84-112 d, were studied under ketamine and pentobarbital anesthesia such that nociceptive reflexes were eliminated. Sound stimuli were presented bilaterally through a calibrated, closed delivery system within a soundattenuated chamber. Single neurons were isolated with glass micropipettes, and responses to tonal stimuli of 50-msec duration with a 4-msec rise/fall time were led into a window discrimator for on-line data analysis. A neuron was first determined to be ipsilaterally excited and contralaterally inhibited, and the discharge rate was monitored as the interaural stimulus level was systematically varied.

\section{Results}

\section{Response to current injection}

The current-voltage characteristics of one LSO neuron are shown in Figure 3. Graded inward current pulses produced proportional increases in the hyperpolarizing electrotonic potential.
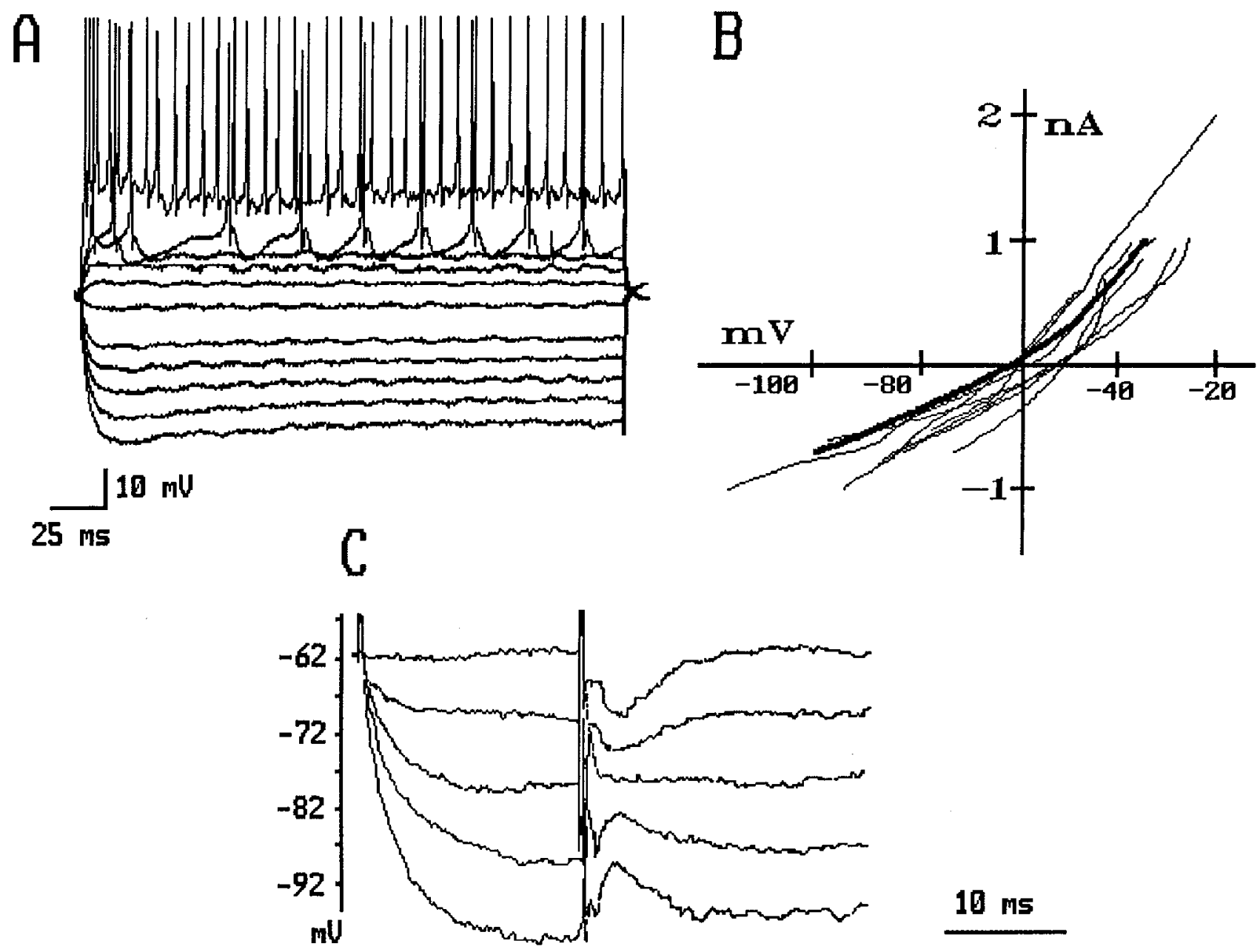

Figure 3. Current-voltage relationships. $A$, The response to 200 -msec current pulses delivered through the intracellular electrode. Current levels were $0.1,0.2,0.3,0.4,1.0,-0.1,-0.2,-0.3,-0.4,-0.5$, and $-0.6 \mathrm{nA}$. The resting potential was $-61 \mathrm{mV}$. $B$, Current-voltage relationships for 8 representative neurons. The bold line is the $I-V$ curve for the neuron shown in $A$. $C$, An IPSP was evoked while delivering current through the electrode. Reversal potential, $-76 \mathrm{mV}$. 
Table 1. Summary of synaptic properties

\begin{tabular}{lccc} 
& EPSPs $(X \pm \sigma)$ & IPSPs $(X \pm \sigma)$ & $\begin{array}{l}\text { Action potential } \\
(X \pm \sigma)\end{array}$ \\
\hline Minimum latency to rise (msec) & $2.2 \pm 0.3$ & $1.8 \pm 0.5$ & $2.9 \pm 0.7^{a}$ \\
Maximum latency to rise (msec) & $3.1 \pm 0.5$ & $3.0 \pm 1.0$ & $4.1 \pm 1.0^{a}$ \\
Minimum latency to peak (msec) & $3.0 \pm 0.5$ & $3.2 \pm 1.0$ & $3.1 \pm 0.7^{a}$ \\
Maximum latency to peak (msec) & $4.0 \pm 0.9$ & $4.9 \pm 2.0$ & $4.3 \pm 1.0^{a}$ \\
Minimum duration (msec) & $1.5 \pm 0.8$ & $3.2 \pm 1.7^{b}$ & $0.7 \pm 0.4^{a}$ \\
Maximum duration (msec) & $4.2 \pm 2.8$ & $8.1 \pm 2.9^{b}$ & $0.9 \pm 0.5^{a}$ \\
Minimum amplitude (mV) & $1.5 \pm 0.8$ & $1.6 \pm 0.7$ & $41 \pm 14$ \\
Maximum amplitude (mV) & $8.7 \pm 3.9$ & $8.3 \pm 2.9$ & $50 \pm 13$ \\
Minimum slope (mV/msec) & $1.8 \pm 1.0$ & $2.0 \pm 0.8$ & $74+35$ \\
Maximum slope (mV/msec) & $10.9 \pm 5.4$ & $9.3 \pm 5.0$ & $102 \pm 34$ \\
Convergence & $9.6 \pm 2.8$ & $8.2 \pm 3.5$ &
\end{tabular}

${ }^{a}$ Measures for action potentials were taken at $1 / 2$ maximum amplitude.

"Significantly greater than EPSP value $(p<0.001 ; t=4.28 ; d f=40)$.

Outward current pulses generally produced a depolarization that declined in amplitude, indicating delayed rectification. The outward current pulses often elicited a large number of action potentials, though this was not always the case. Some neurons discharged only a single time at the onset of the current pulse.
The mean input resistance, $R_{\text {inpul }}$ was $42 \pm 21 \mathrm{M} \Omega$, and the mean time constant, $\tau$, was $1.1 \pm 0.4 \mathrm{msec}(X \pm \sigma ; N=15)$. It was also possible to reverse the contralaterally evoked IPSPs by hyperpolarizing the neuron. As shown in Figure 3, the reversal potential for IPSPs was generally $-75 \mathrm{mV}$.

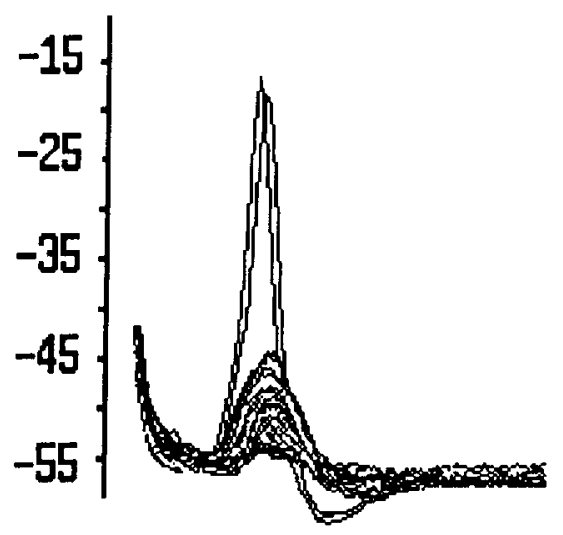

$\mathrm{mU}$

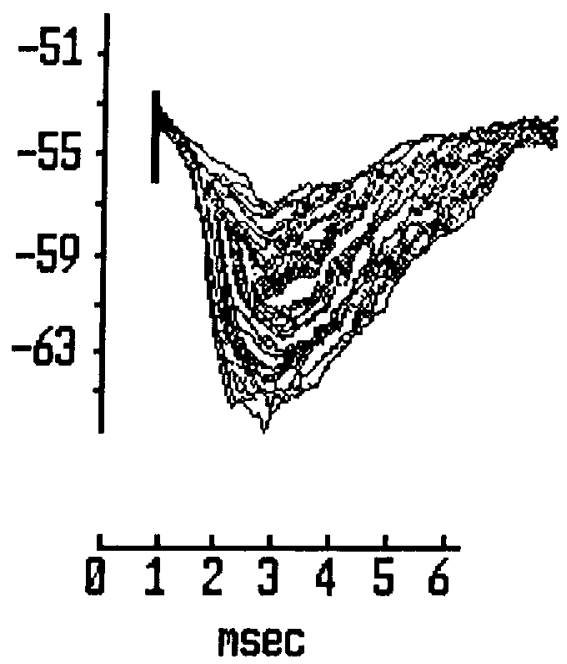

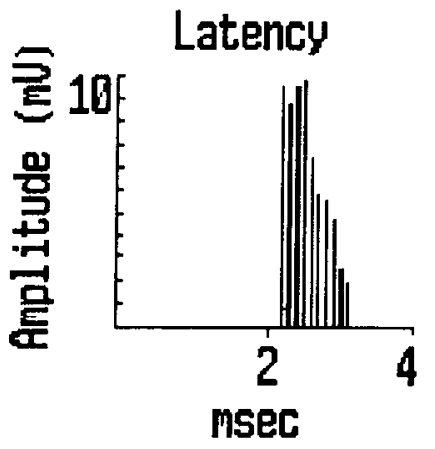
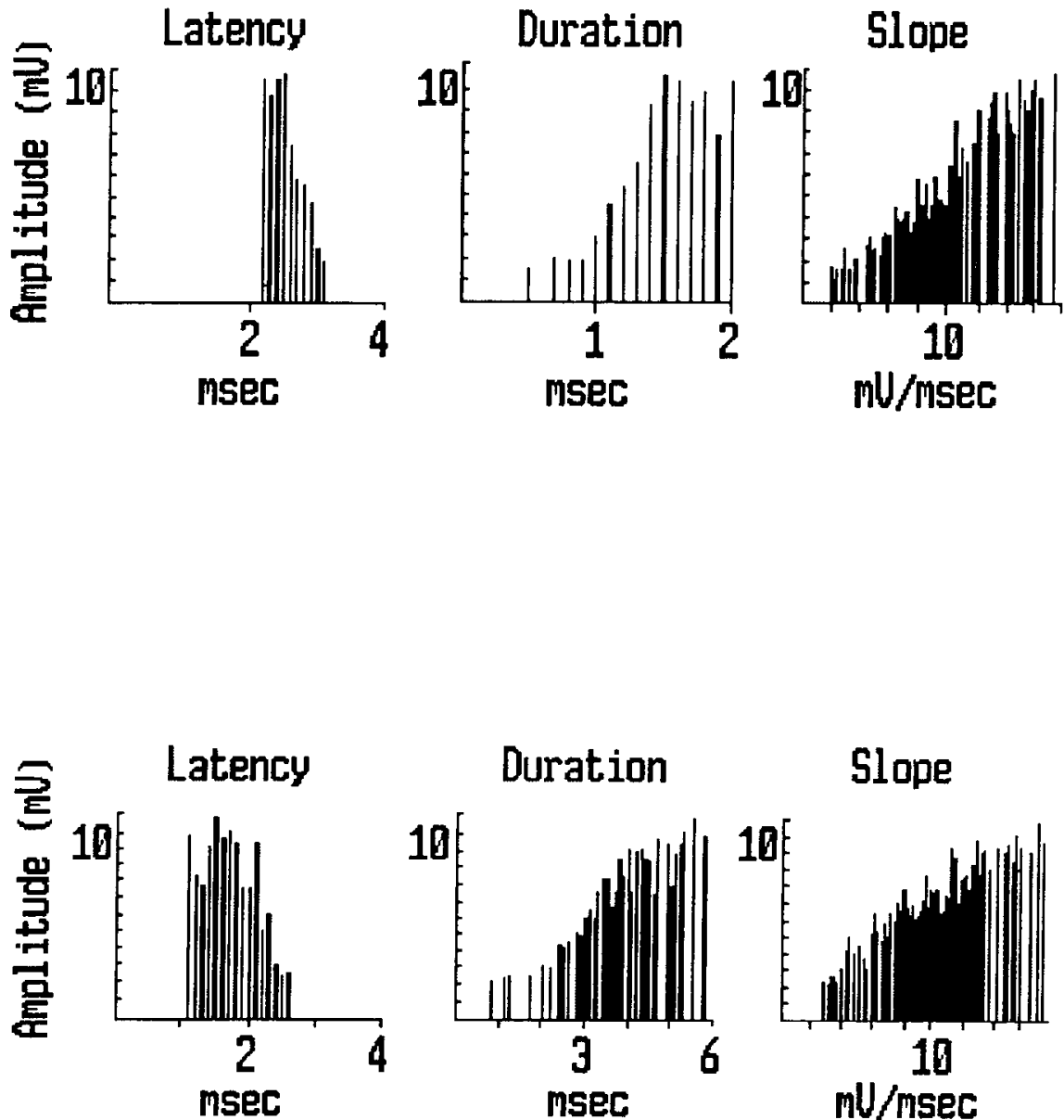

Duration

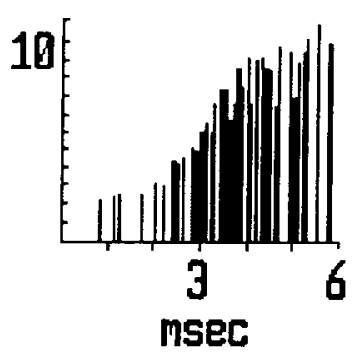

Slope

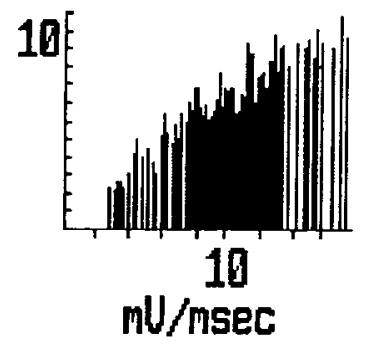

Figure 4. Typical synaptic responses and analyses. Left, A family of EPSPs/action potentials (top) and IPSPs (bottom) evoked by incremental stimuli to either the ipsilateral or contralateral pathway, respectively. Right, Analyses of latency to rise, duration, and rising slope are shown for both sets of traces. It was commonly found that larger amplitude potentials had shorter latencies, longer durations, and greater rising slopes. 
A
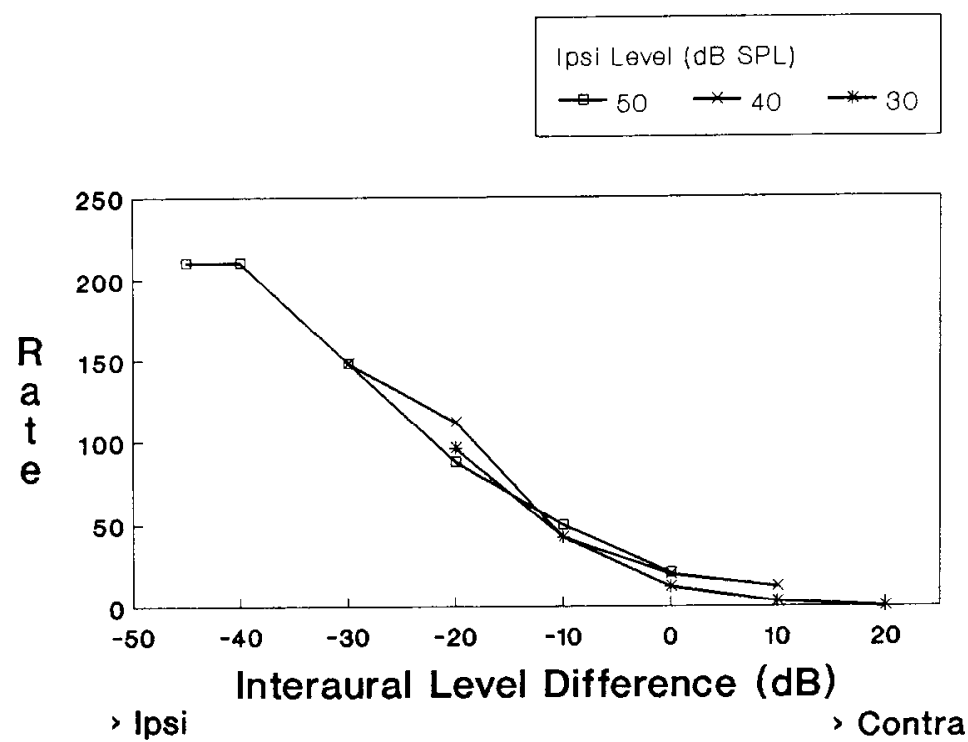

B

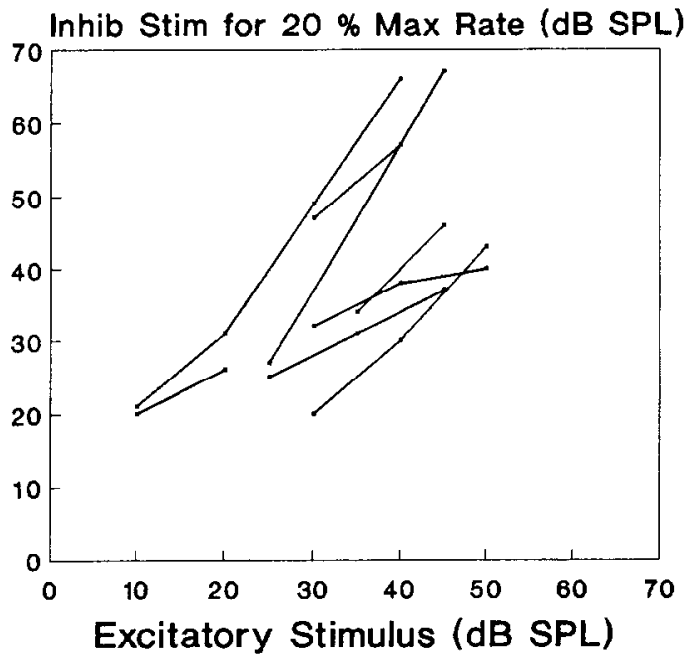

Figure 5. Response to sound-level differences. $A$, The response of a single LSO neuron to interaural level difference is shown for 3 ipsilateral levels. In order to decrease the discharge rate to $20 \%$ of the maximal rate (e.g., to approximately 40 discharges/sec), it was necessary to increase the contralateral level for each increase in ipsilateral level. $B$, For neurons recorded in vivo, the ipsilateral sound level used to elicit a burst of action potentials from an LSO neuron is plotted against the contralateral sound level that was necessary to reduce discharge rate to criterion (i.e., $20 \%$ of maximal discharge rate). Note the positive correlation between stimulus levels.

\section{Response to electrical stimuli}

Stimulus-evoked postsynaptic potentials (PSPs) were recorded and subjected to 5 simple analyses (Fig. 2). Electrical stimuli delivered to the ipsilateral pathway commonly evoked EPSPs and action potentials, and electrical stimuli delivered to the contralateral pathway commonly evoked IPSPs. An example of each response is shown in Figure 4, in which latency, duration, and slope are graphically summarized. For both sets of potentials, there was a consistent relationship between these 3 parameters and maximum PSP amplitude. The largest amplitude potentials commonly had the shortest latencies, the longest durations, and the steepest slopes. The parametric analyses of EPSPs, IPSPs, and action potentials are shown in Table 1. For example, the minimum latency to rise was $2.2 \mathrm{msec}$ for EPSPs and $1.8 \mathrm{msec}$ for IPSPs. The measures of latency and slope were nearly identical for EPSPs and IPSPs.

There was, however, one major difference between excitatory and inhibitory synaptic events: the duration of IPSPs was twice that of EPSPs. The mean maximum duration for EPSPs was $4.2 \mathrm{msec}$, while that for IPSPs was $8.1 \mathrm{msec}(p<0.001, t=$ 4.28). This duration could lead to significant temporal summation at afferent discharge rates above $150 \mathrm{~Hz}$.

Although the amount of synaptic convergence onto each LSO neuron was quite large, it was possible to estimate the number of afferents innervating a single LSO neuron based on physiological criteria. The area between each PSP and the resting potential baseline was computed for incremental stimuli, and the number of quantal increases in area was determined (see Materials and Methods). The mean number of subthreshold EPSPs was estimated to be 9.6 , and the mean number of IPSPs was estimated to be 8.2 .

\section{Sound stimuli: binaural integration}

The basic response of LSO neurons to sound-level differences was analyzed in vivo. Single LSO neurons produced lower dis- charge rates as the contralateral sound level increased relative to the ipsilateral sound level (Fig. 5). In the example shown, when an ipsilateral sound level of $30 \mathrm{~dB}$ sound pressure level (SPL) stimulus was used, a contralateral sound level of $30 \mathrm{~dB}$ SPL was necessary to inhibit most action potentials. When the ipsilateral level was increased to $40 \mathrm{~dB} \mathrm{SPL}$, it was also necessary to increase the contralateral level to $40 \mathrm{~dB}$ SPL to yield the same discharge rate.

This property was examined for several LSO neurons, and the contralateral sound level that decreased discharge to $20 \%$ of its maximal rate was determined for increasing ipsilateral levels. As shown in Figure 5, there was a commensurate rise in ipsilateral and contralateral sound level to yield the same discharge rate. The average slope for all neurons examined was $0.85 \pm 0.4(X \pm \sigma ; N=24)$.

\section{Electrical stimuli: integration of bilateral electrical stimuli}

In order to determine whether LSO neurons in vitro were able to integrate the 2 afferent pathways in a manner similar to that seen in vivo, conjoint stimuli were used. First, the ipsilateral voltage pulse was adjusted until an action potential was elicited. Concurrent stimuli were then delivered to the contralateral pathway to determine whether the action potential could be blocked. An example of such an experiment is shown in Figure 6. An action potential, elicited by a $12-\mathrm{V}$ stimulus, was inhibited when a 6-V stimulus was delivered to the contralateral pathway. When the action potential was elicited by a $25-\mathrm{V}$ stimulus, the contralateral stimulus was raised to $11 \mathrm{~V}$ in order to inhibit it.

The contralateral voltage necessary to block an action potential that was evoked by each ipsilateral stimulus voltage was plotted for several LSO neurons (Fig. 7). In 20 of 22 neurons, there was a commensurate rise in the ipsilateral and the contralateral stimulus voltage to yield the same response (i.e., blockade of the evoked action potential).

An LSO neuron commonly responds to sound stimuli with 

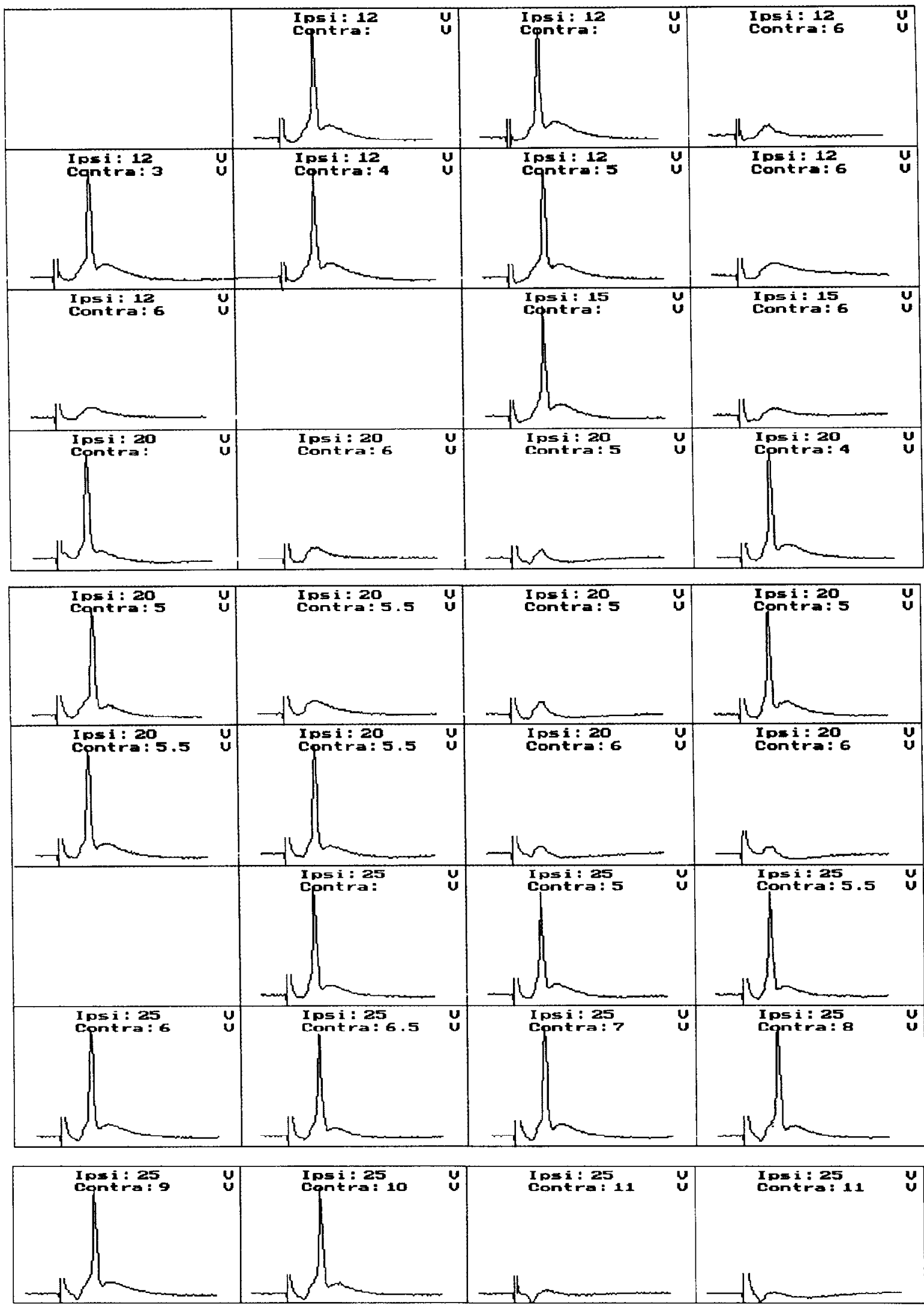

Figure 6. Integration of 2 pathways by LSO neurons: intracellularly recorded responses of LSO neuron to electrical stimuli. Each panel shows a stimulus-evoked response for ipsilateral stimuli alone or with a conjoint stimulus to the contralateral pathway. The first panel shows that a $12-\mathrm{V}$ stimulus evoked an action potential. The stimulus amplitude to the contralateral pathway was adjusted to reveal the threshold for inhibiting this action potential: $6 \mathrm{~V}$. When the ipsilateral stimulus amplitude was raised to $25 \mathrm{~V}$ (row 7), the evoked action potential was only inhibited if the contralateral stimulus amplitude was also raised to $11 \mathrm{~V}$. 

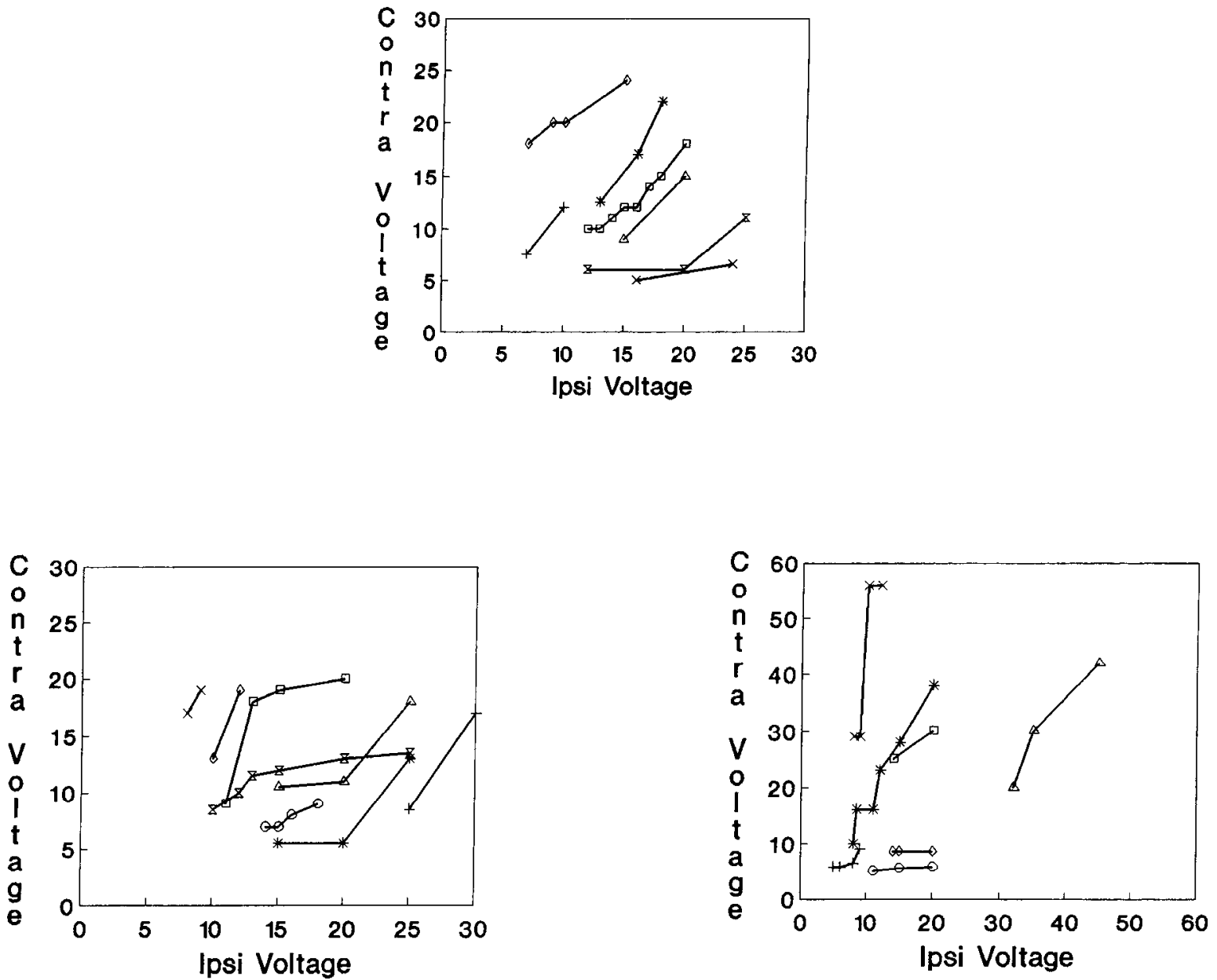

Figure 7. Correlation of excitatory and inhibitory stimuli. For neurons recorded in vitro, the ipsilateral stimulus voltage used to elicit a single action potential is plotted against the contralateral stimulus voltage that was necessary to suppress the single discharge. Note the positive correlation between stimulus levels. Symbols represent different cells.

several action potentials, depending on the stimulus duration. The discharge rate varies directly with the interaural level difference (Fig. 5). In order to mimic this integration of bilateral stimuli over time, repetitive stimuli were delivered concurrently to both pathways. As shown in Figure 8, it was possible to evoke a burst of action potentials without appreciable fatigue. With the addition of submaximal stimuli to the contralateral pathway, it was found that a fraction of the evoked action potentials could be suppressed. With the addition of maximal contralateral stimuli, it was possible to suppress all evoked action potentials. Therefore, intermediate discharge rates emerged when contralateral stimulus voltage was gradually increased.

As shown in Figure 9, intermediate discharge rates were apparent in all neurons tested. In 4 cases, it was possible to repeat the stimulus regimen for 2 ipsilateral stimulus voltages. It was found for 3 of these neurons that the larger ipsilateral voltages necessitated an increase in contralateral voltage to yield the same discharge rate. The contralateral stimuli initially inhibited the latter-occurring evoked action potentials in a burst (Fig. 10). As the contralateral voltage was increased still further, the first action potential was also blocked.

\section{Temporal characteristics of the synaptic response}

The integration of evoked action potentials and IPSPs depended, partially, on 2 temporal parameters: the shift in latency with stimuli of increasing amplitude and the total time during which an IPSP was able to suppress a discharge. The latency to rise and to peak was examined for action potentials and IPSPs elicited by stimuli of increasing amplitude. As illustrated in Figure 11 , it was commonly found that the latency to rise was shortened as the stimulus voltage was raised. The difference between minimum and maximum latencies is shown in Table 1. There was an approximate $1-\mathrm{msec}$ differential for both action potentials and IPSPs as the stimulus level was raised.

The time range during which an IPSP was able to suppress an action potential was detcrmined by varying the stimulus latency to each pathway in $0.1-\mathrm{msec}$ increments. As shown in Figure 12, when one stimulus was delayed relative to the other, it was possible to determine the discrete time during which inhibition was effective at suppressing an action potential. Although it was beyond the scope of the present study to quantify this parameter, inhibitory potentials were generally efficacious for at least $1 / 2$ their total duration.

\section{Discussion}

Almost every central neuron integrates several synaptic inputs to calculate the characteristics of its response. In the central auditory system, one of the best-studied response properties is the correlation of neuron discharge rate to sound stimulus lo- 

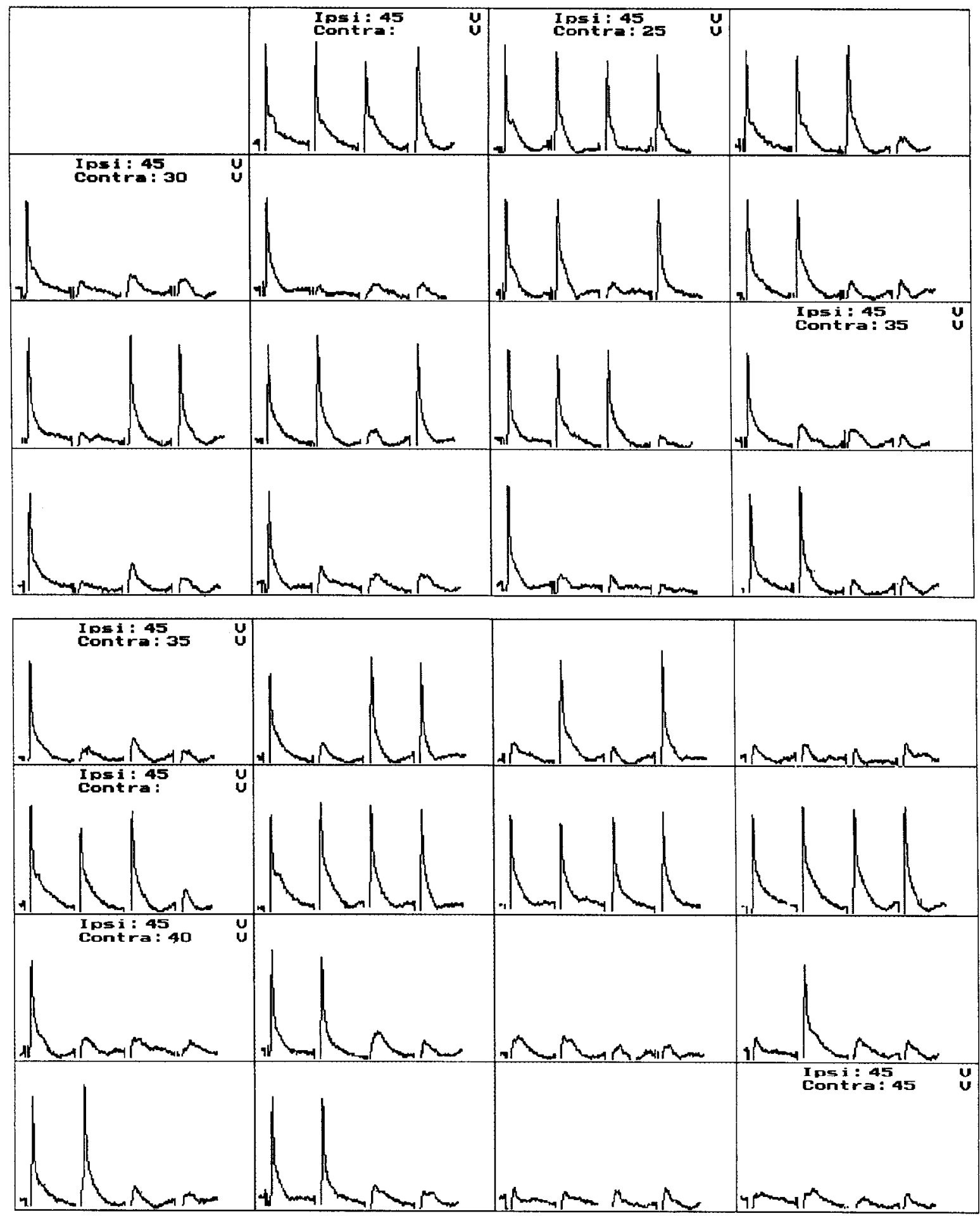

Figure 8. Effect of stimulus duration. Multiple action potentials were evoked by a stimulus rate of 50 pulses/sec delivered to the ipsilateral pathway for $60 \mathrm{msec}$. In the top left panel, 4 action potentials were evoked by $45-\mathrm{V}$ stimulus pulses delivered to the ipsilateral pathway. The fourth and fift row of panels show that most of these action potentials were blocked by coincident contralateral stimuli of $35 \mathrm{~V}$, also delivered at 50 pulses/ sec. $\Lambda t$ intermediate contralateral voltages, only a fraction of the action potentials were blocked. Therefore, the integration of excitatory and inhibitory responses may produce a graded change in discharge rate when longer-duration stimulus regimens are used. This is reminiscent of the gradual change in discharge rate seen in vivo as interaural level difference is modulated.

cation (Suga, 1984; Yin and Kuwada, 1984; Konishi et al., 1988; Middlebrooks, 1988). A major objective of this study was to examine the integration of excitatory and inhibitory synaptic potentials in LSO neurons that encode binaural level differences (Boudreau and Tsuchitani, 1970; Sanes and Rubel, 1988). The brain-slice preparation is advantageous in that one can selectively assay specific elements in a complex pathway. In the present study, functional characteristics of LSO neurons cannot be attributed to the cochlear nuclei, because these elements were bypassed with the stimulating electrodes. 

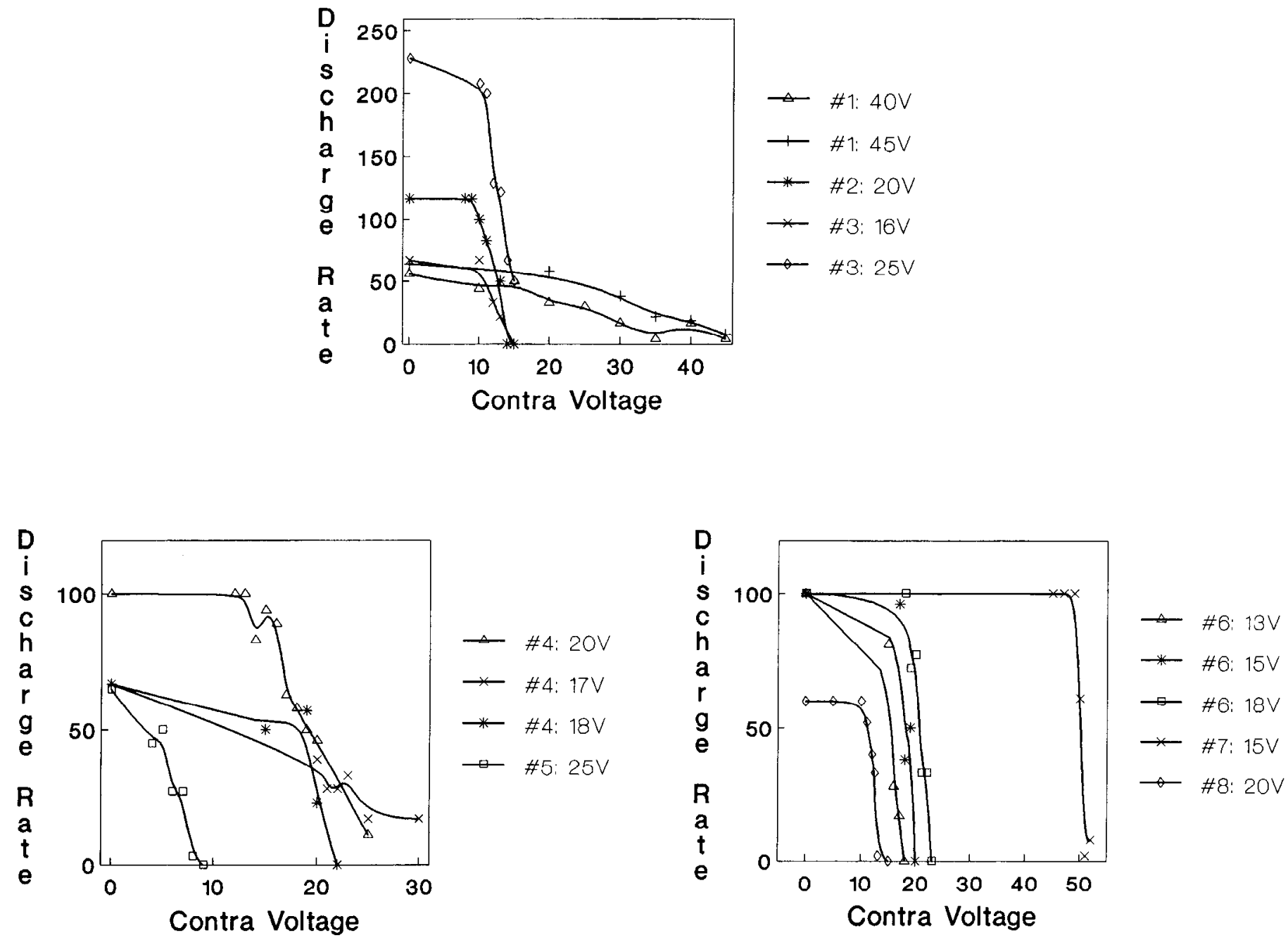

Figure 9. Intermediate discharge rates. Plots of discharge rates are shown for 8 neurons subjected to the stimulus paradigm illustrated in Figure 8. For a given ipsilateral stimulus voltage, a fraction of the evoked discharges could be blocked by stimuli delivered to the contralateral pathway. This property is similar to the intermediate discharge rates produced by LSO neurons in vivo to changes in interaural sound level (see Fig. $5 A$ ).

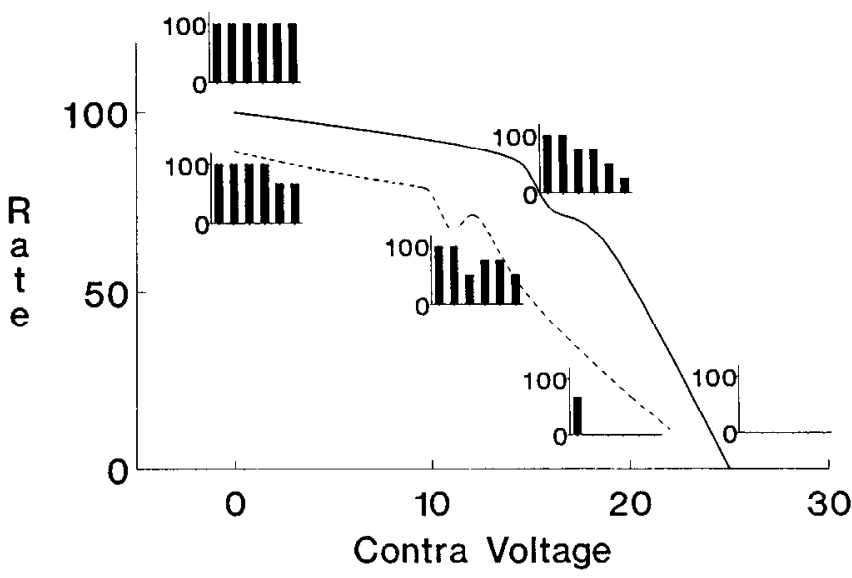

Figure 10. Latter action potentials are first to be inhibited. A plot of discharge rate versus contralateral stimulus voltage is shown for 2 ipsilateral stimuli at $15 \mathrm{~V}$ (broken line) and $17 \mathrm{~V}$ (solid line). An increase in the ipsilateral voltage caused a concomitant increase in contralateral voltage to yield the same discharge rate. Stimuli were delivered at a rate of $100 \mathrm{~Hz}$ for $60 \mathrm{msec}$, and ipsilateral pulses evoked up to 6 action potentials. Histograms of the average discharge rate for representative stimuli are shown. When stimuli to the contralateral pathway were given concurrently, it was found that the latter-occurring action potentials were the first to be inhibited.

\section{Synaptic properties}

The predominant synaptic potentials evoked with electrical stimuli were identical to those seen in vivo (Finlayson and Caspary, 1989). Electrical stimuli delivered to the ipsilateral afferent pathway emerging from the anteroventral cochlear nucleus were found to evoke EPSPs or an action potential (Fig. 4). Elcctrical stimuli delivered to the contralateral pathway emerging from the ipsilateral MNTB were found to evoke IPSPs (Fig. 4). There were a modest number of synaptic responses that did not conform to this classification. Because higher-level stimulus voltages were often found to yield these sorts of responses, it was possible that current spread from the stimulating electrode may have recruited remote afferents. However, it is likely that some of these responses reflect in vivo mechanisms (Brownell et al., 1979).

There were several distinct characteristics of the evoked synaptic potentials (Table 1). The latency to rise and peak was nearly identical for EPSPs and IPSPs. Although latency to rise was primarily a consequence of electrode placement, the stimulating electrode positions were equidistant from most recording sites. Therefore, the propagation velocity and synaptic delay from the points of stimulation to the LSO neuron appear to be quite well matched for the 2 pathways. 


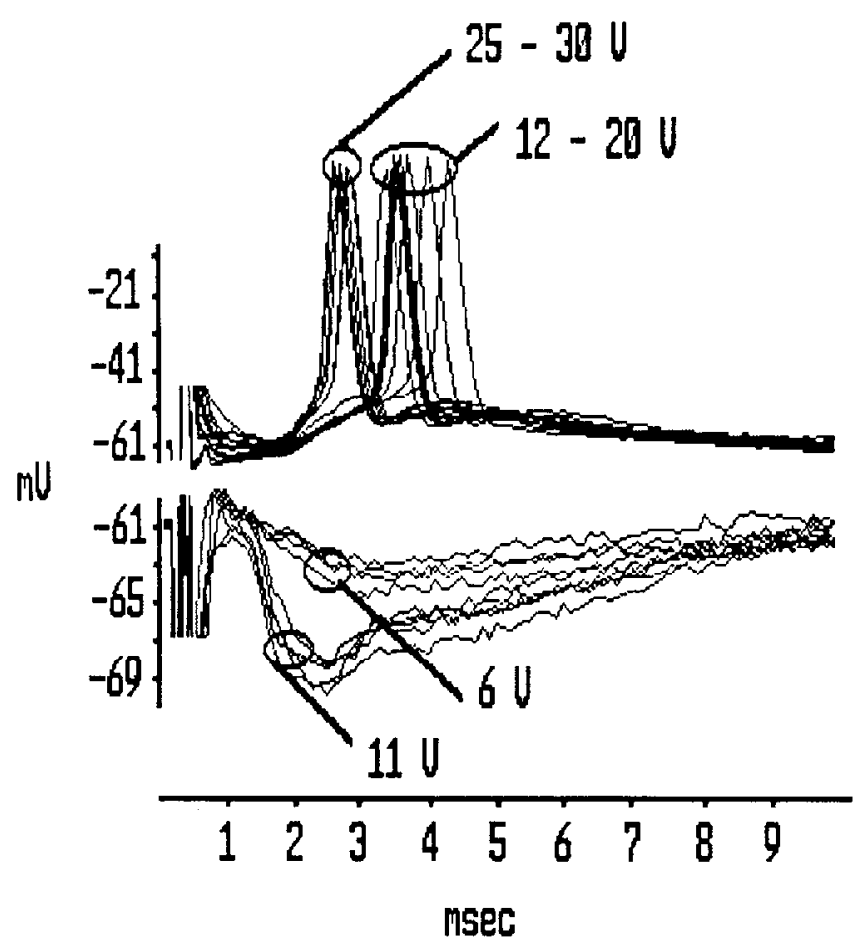

Figure 11. Effect of stimulus voltage on latency. The latencies of both ipsilaterally evoked action potentials and contralaterally evoked IPSPs were decreased with greater stimulus voltage. The integration of these 2 pathways is shown in Figure 6 for this neuron. It was found that action potentials evoked by $12-20-\mathrm{V}$ stimuli were blocked by $6-\mathrm{V}$ stimuli to the contralateral pathway. However, action potentials evoked by $25-$ $30-\mathrm{V}$ stimuli were only blocked when contralateral stimuli were increased to $11 \mathrm{~V}$. Therefore, it is possible that the short action-potential latency (25-30-V stimuli) was temporally removed from inhibition.

It was generally found, as stimulus voltage was elevated and PSP amplitude increased, that there was a concomitant decrease in the latency and increase in the duration and rising slope (Fig. 4). These relationships were found for both EPSPs and IPSPs. When considering the manner in which LSO neurons integrate EPSPs and IPSPs, one must take these dynamic temporal properties into account. That is, a large stimulus voltage (or highlevel sound source) does more than evoke a larger amplitude PSP. It also changes the time at which an action potential occurs or the time at which a hyperpolarizing potential is attained (Fig. 11).

A significant difference existed in the duration of EPSPs and IPSPs. The inhibitory potentials were, on average, 2 times that of excitatory potentials. A relatively longer period of inhibition has previously been noted in studies on central auditory neurons (Erulkar, 1959; Nelson and Erulkar, 1963; Aitkin and Dunlop, 1968; Kitzes et al., 1980; Yin et al., 1985). The extended duration of IPSPs may allow for significant temporal summation at MNTB discharge rates greater than approximately $150 \mathrm{~Hz}$ (e.g., at higher sound levels). The duration of IPSPs varies greatly between neural systems. For example, the amplitudes and durations of IPSPs in trochlear motoneurons are several-fold greater than those in abducens motoneurons (Precht and Baker, 1972; Spencer et al., 1989). The cellular basis of this IPSP diversity may involve a voltage dependence of glycine-activated $\mathrm{Cl}^{-}$channels (Faber and Korn, 1987).

The current-voltage curves obtained for LSO neurons showed a linear relationship for inward current pulses and a delayed

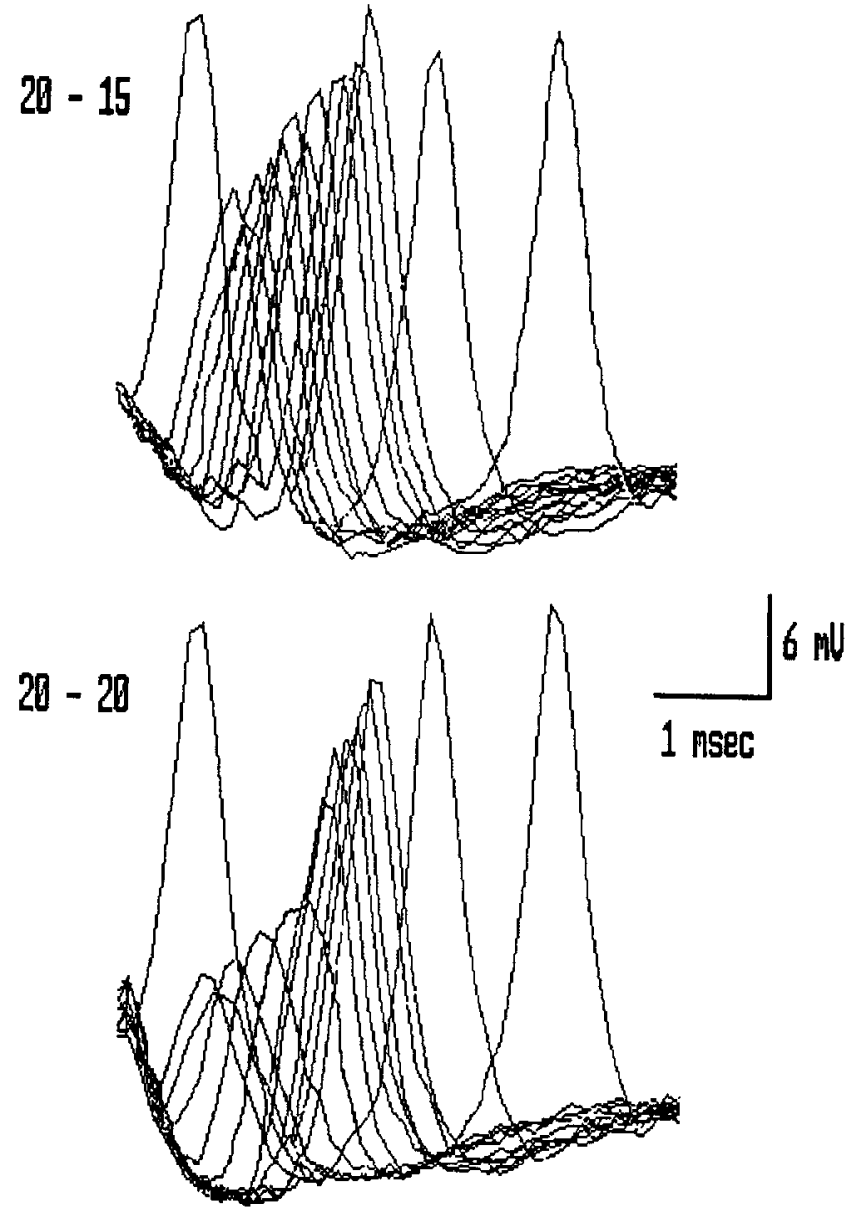

Figure 12. Effect of timing on synaptic integration. The excitatory stimulus was triggered at increasing latencies relative to the inhibitory stimulus. In this way, the effective duration of an IPSP was determined. Top, When a $20-\mathrm{V}$ stimulus was used to evoke an action potential, a 15 -V stimulus to the contralateral pathway was barely able to suppress the discharge. Bottom, When a $20-\mathrm{V}$ stimulus was used to evoke an action potential, a $20-\mathrm{V}$ stimulus to the contralateral pathway was sufficient to suppress a discharge for about $1 \mathrm{msec}$. The stimulus artifacts were removed for clarity.

rectification for outward current pulses (Fig. 3B). Some neurons responded to 200-msec outward current pulses with a continuous burst of action potentials, while others responded with a single action potential. Until a large sample size is accumulated and compared to in vivo recordings, it will be difficult to determine whether subtle differences in biophysical characteristics are due to the in vitro conditions or reflect genuine differences. The passing of hyperpolarizing current demonstrated that the IPSP reversal potential was approximately $-75 \mathrm{mV}$ (Fig. 3C). This is consistent with the inhibitory receptor being a glycinegated chloride channel (Moore and Caspary, 1983; Sanes et al., 1987; Wenthold and Altschuler, 1987).

There exists a possibility that gerbil central auditory function is compromised by the accumulation of extracellular vacuoles in several brain-stem nuclei (Ostapoff and Morest, 1989). However, all in vivo assays of auditory function indicate that coding properties and psychophysical abilities are fully intact (Finck et al., 1972; Ryan, 1976; Smith, 1977, 1979; Ozdamar and Dallos, 1978; Goodman et al., 1982; Frisina et al., 1982, 1985, 1989a,b; Ryan et al., 1982; Harris and Dallos, 1984; Melzer, 1984; Woolf and Ryan, 1984, 1985; Dolan et al., 1985; Semple and Kitzes, 
1985, 1987; Heffner and Heffner, 1988; Sanes and Rubel, 1988; Sanes et al., 1989).

\section{Binaural integration}

Neurons in the gerbil LSO demonstrated 2 simple response properties in vivo to acoustic stimuli that were amenable to in vitro analysis. First, it was commonly found that ipsilateral and contralateral sound levels had to be increased simultaneously in order to yield the same response criterion (Fig. 5). A similar commensurate rise in ipsilateral and contralateral stimulus level has been reported for neurons in the cat LSO (Boudreau and Tsuchitani, 1970; see their figure 44). This attribute favors binaural level differences rather than changes in average level. Therefore, there must be a cellular mechanism for representing incremental sound levels in both the excitatory and the inhibitory pathway to the LSO.

A second characteristic of LSO neurons was the correlation of intermediate discharge rates in response to binaural level differences (Fig. 5). The generation of intermediate discharge rates was a function of stimulus duration. Similarly, the detection of interaural level and time differences by humans improves with stimulus duration (Hafter et al., 1979). Therefore, it is likely that intermediate discharge rates are a consequence of both the number of afferents recruited (i.e., sound level) and the history of afferent discharge.

\section{Bilateral integration in vitro}

LSO neurons in vitro exhibited 2 response properties to electrical stimulation that strongly resembled acoustically evoked characteristics. First, when a discharge was evoked with incremental stimuli to the ipsilateral pathway, it was also necessary to increase the contralateral stimulus voltage required to suppress the action potential (Figs. 6,7). This suggests that the synaptic current underlying the action potential has increased, that the latency to discharge has changed, or both. In order to inhibit the action potential evoked by large-amplitude stimuli, there must be a concomitant change in the amplitude and/or latency of synaptically evoked hyperpolarizations. A good correlation between stimulus voltage and latency has been found (Fig. 11), and its contribution to bilateral integration is now being tested.

The positive correlation between the ipsilateral and contralateral stimulus levels required to yield a criterion response was consistent for both in vivo and in vitro recordings. This property may be related to the number of excitatory and inhibitory afferents that innervate each LSO neuron. An estimate of these values, based on electrophysiological criteria, indicated that there were roughly 10 excitatory and 8 inhibitory afferents per LSO neuron (Table 1). Because the estimate of excitatory afferents did not include those above the neurons' threshold to discharge, it is likely that there are more excitatory afferents per LSO neuron than inhibitory afferents. As more afferents were recruited by incremental voltage stimuli, the synaptic current increased, and the latency to rise decreased. The shortening of contralateral inhibitory latency with increases in sound stimulus level has previously been demonstrated with acoustic stimuli in the cat LSO (Tsuchitani, 1988a). It is important to note that the order in which afferents are recruited by sound stimuli may lead to response properties that are far more refined than those described for electrical stimuli. For this reason, the response properties obtained from the brain-slice preparation appear to be particularly robust.

The second in vitro response property that resembled an in vivo phenomenon was the generation of intermediate discharge rates. The neural response to longer-duration sounds was mimicked by evoking action potentials with a burst of electrical stimulus pulses to the ipsilateral pathway. A range of incremental contralateral voltages blocked an increasing fraction of the evoked action potentials (Figs. 8, 9). This resembled the intermediate discharge rates produced by varying interaural sound level (Fig. 5).

The discharge rate was determined by averaging several trials, just as single-neuron poststimulus-time histograms are generated in vivo. In general, the latter-occurring action potentials were the first to be inhibited by contralateral stimulation (Fig. 10 ). This implies that the efficacy of inhibition becomes relatively greater than that of excitation as stimulation proceeds. It is now possible to test whether this emergent property is a result of IPSP duration and spatial summation, or due to the rate of fatigue in each afferent pathway. These parameters are presently being evaluated.

\section{Relevance to sound localization}

The results from in vitro recordings suggest 2 general mechanisms by which binaural level differences may initially be computed in the LSO. First, there is a substantial convergence of afferents from each pathway. The sequential recruitment of afferents may lead to a simple summation of synaptic currents and a discharge rate commensurate with the resulting membrane potential. The relative insensitivity of LSO neurons to average binaural level may also depend on this convergence. As average sound level increases, a greater number of afferents and larger synaptic currents are recruited from both pathways.

The second mechanism is suggested by the temporal changes in synaptic potentials as stimulus level is raised: The latencies decreased and the rising slopes increased (Figs. 4, 11). It is possible that increases in sound level serve to sequentially recruit afferents, and the spatial summation of the synaptic currents produce action potentials and IPSPs with shorter latencies. In this case, the probability that an action potential can be inhibited is dependent on its temporal position with respect to the evoked IPSP (Fig. 11).

It has been shown that the responses of binaural neurons that are maximally sensitive to interaural level differences are modulated with brief interaural time differences (Brugge et al., 1969; Kitzes et al., 1980; Caird and Klinke, 1983; Yin et al., 1985; Pollak, 1988). These interaural time differences are larger than those that would be produced by free-field acoustic stimuli. Rather, they reflect the relative latency of afferent discharge from the excitatory and inhibitory pathway to the binaural neuron. For example, an increase in sound level to the excitatory ear changes the effective interaural time difference that modulates the response. Therefore, sound level is converted into a temporal cue by the central auditory system.

These temporal coding properties may also contribute to the localization of high-frequency stimuli that are amplitude modulated at 50-600 Hz (Henning, 1974; McFadden and Pasanen, 1976; Yost, 1976; Nuetzel and Hafter, 1981; Hafter et al., 1988). It has previously been shown that some neurons in the inferior colliculus with high characteristic frequency are able to encode interaural time differences (Yin et al., 1984).

The integration of sound stimuli clearly improves with longer stimulus durations (Tobias and Zerlin, 1959; Hafter et al., 1979). Because the temporal structure of an LSO neuron response to interaural level differences is dynamic, it may provide additional 
information about binaural level differences and average level (Tsuchitani, 1988a,b). The present results suggest that temporal discharge is partially dependent on the history of afferent discharge. The latter-occurring evoked action potentials were most susceptible to inhibition by any given stimulus voltage, and larger voltages resulted in the suppression of the first discharge (Fig. 10). This emergent property of bilateral integration may be obtained from either the temporal summation of IPSPs or a difference between excitatory and inhibitory synaptic fatigue.

The present results indicate that some aspects of binaural interaction are amenable to cellular analysis in vitro. The relative contribution of specific temporal mechanisms to bilateral integration may now be evaluated. To the extent that in vitro response properties reflect the synaptic integration performed in vivo, it is now possible to examine the ontogeny of a relatively simple computational circuit.

Note added in proof: This article was completed prior to the publication of a relevant review article (Glickstein and Yeo, 1990).

\section{References}

Aitkin LM, Dunlop CW (1968) Interplay of excitation and inhibition in the cat medial geniculate body. J Ncurophysiol 31:44-61.

Boudreau JC, Tsuchitani C (1968) Binaural interaction in the cat superior olive s-segment. J Neurophysiol 31:442-454.

Boudreau JC, Tsuchitani C (1970) Cat superior olive s-segment cell discharge to tonal stimulation. In: Contributions to sensory physiology, Vol 4 (Neff WD, ed), pp 143-213. New York: Academic.

Brownell WE, Manis PB, Ritz LA (1979) Ipsilateral inhibitory responses in the cat lateral superior olive. Brain Res 177:189-193.

Browner RH, Webster DB (1975) Projections of the trapezoid body and the superior olivary complex of the Kangaroo rat (Dipodomys merriami). Brain Behav Evol 11:322-354.

Brugge JF, Dubrovsky NA, Aitkin LM, Anderson DJ (1969) Sensitivity of single neurons in auditory cortex of cat to binaural tonal stimulation; effects of varying interaural time and intensity. J Neurophysiol 32:1005-1024.

Brugge JF, Anderson JF, Aitkin LM (1970) Responses of neurons in the dorsal nucleus of the lateral lemniscus of cat to binaural tonal stimulation. J Neurophysiol 33:441-458.

Caird D, Klinke R (1983) Processing of binaural stimuli by cat superior olivary complex neurons. Exp Brain Res 52:385-399.

Cant NB, Casseday JH (1986) Projections from the anteroventral cochlear nucleus to the lateral and medial superior olivary nuclei. J Comp Neurol 247:457-476.

Dolan TG, Mills JH, Schmiedt RA (1985) A comparison of brainstem, whole-nerve AP and single-fiber tuning curves in the gerbil: normative data. Hearing Res 17:259-266.

Durlach NI, Colburn HS (1978) Binaural phenomena. In: Handbook of perception, Vol 4 (Carterette EC, Friedman MP, eds), pp 365-466. New York: Academic.

Erulkar SD (1959) The response of single units of the inferior colliculus of the cat to acoustic stimulation. Proc R Soc London [Biol] 150:336355.

Faber DS, Korn H (1987) Voltage-dependence of glycine-activated $\mathrm{Cl}^{-}$channels: a potentiometer for inhibition? J Neurosci 7:807-811.

Feddersen WE, Sandel TT, Teas DC, Jeffress LA (1957) Localization of high frequency tones. J Acoust Soc Am 29:988-991.

Finck A, Schneck CD, Hartman AF (1972) Development of cochlear function in the neonate Mongolian gerbil (Meriones unguiculatus). $\mathrm{J}$ Comp Physiol Psychol 78:375-380.

Finlayson PCr, Caspary DM (1989) Synaptic potentials of chinchilla lateral superior olivary neurons. Hearing Res 38:221-228.

Frisina RD, Chamberlain SC, Brachman ML, Smith RL (1982) Anatomy and physiology of the gerbil cochlear nucleus: an improved surgical approach for microelectrode studies. Hearing Res 6:259-275.

Frisina RD, Smith RL, Chamberlain SC (1985) Differential encoding of rapid changes in sound amplitude by second-order auditory neurons. Exp Brain Res 60:417-422.
Frisina RD, Smith RL, Chamberlain SC (1989a) Encoding of amplitude modulation in the gerbil cochlear nucleus: I. A hierarchy of enhancement. Hearing Res 44:99-122.

Frisina RD, Smith RL, Chamberlain SC (1989b) Encoding of amplitude modulation in the gerbil cochlear nucleus: II. Possible neural mechanisms. Hearing Res 44:123-142.

Fuzessery ZM, Pollak GD (1985) Determinants of sound localization selectivity in bat inferior colliculus: a combined dichotic and freefield stimulation study. J Neurophysiol 54:757-781.

Glendenning KK, Hutson KA, Nudo RJ, Masterton RB (1985) Acoustic chiasm II: anatomical basis of binaurality in lateral superior olive of cat. J Comp Neurol 232:261-285.

Glickstein M, Yeo C (1990) The cerebellum and motor learning. J Cognitive Neurosci 2:69-80.

Goldberg JM, Brown PB (1969) Response of binaural neurons of dog superior olivary complex to dichotic tonal stimuli: some physiological mechanisms of sound localization. J Neurophysiol 32:613-636.

Goodman DA, Smith RL, Chamberlain SC (1982) Intracellular and extracellular responses in the organ of Corti of the gerbil. Hearing Res 7:161-179.

Hafter ER, Dye RII Jr, Gilkey RH (1979) Lateralization of tonal signals which have neither onsets nor offsets. J Acoust Soc Am 65: $471-477$.

Hafter ER, Buell TN, Richards VM (1988) Onset-coding in lateralization: its form, site, and function. In: Auditory function: neurobiological bases of hearing (Edelman GM, Gall WE, Cowan WM, eds), pp 647-676. New York: Wiley.

Harnischfeger G, Neuweiler G, Schlegel P (1985) Interaural time and intensity coding in superior olivary complex and inferior colliculus of the echo locating bat Molossus ater. J Neurophysiol 53:89-109.

Harris D, Dallos P (1984) Ontogenetic changes in frequency mapping in a mammalian cochlea. Science 225:741-743.

Heffner RS, Heffner HE (1988) Sound localization and use of binaural cues by the gerbil (Meriones unguiculatus). Behav Neurosci 102:422428.

Henning GB (1974) Detectability of interaural delay in high-frequency complex waveforms. J Acoust Soc Am 55:84-90.

Jackson H, Parks TN (1982) Functional synapse elimination in the developing avian cochlear nucleus with simultaneous reduction in cochlear nerve axon branching. J Neurosci 2:1736-1743.

Kitzes LM, Wrege KS, Cassaday JM (1980) Patterns of responses of cortical cells to binaural stimulation. J Comp Neurol 192:455-472.

Konishi M, Takahashi TT, Wagner H, Sullivan WE, Carr CE (1988) Neurophysiological and anatomical substrates of sound localization in the owl. In: Auditory function: neurobiological bases of hearing (Edelman GM, Gall WE, Cowan WM, eds), pp 721-745. New York: Wiley.

Lichtman J (1977) The reorganization of synaptic connexions in the rat submandibular ganglion during postnatal development. J Physiol (Lond) 273:155-177.

Mariani J, Changeux J-P (1981) Ontogenesis of olivocerebellar relationships. I. Studies by intracellular recordings of the multiple innervation of Purkinje cells by climbing fibers in the developing rat cerebellum. J Neurosci 1:696-702.

McFadden D, Pasanen EG. (1976) Lateralization at high frequencies based on interaural time differences. J Acoust Soc Am 59:634-639.

Melzer P (1984) The central auditory pathway of the gerbil Psammomys obesus: a deoxyglucose study. Hearing Res 15:187-195.

Middlebrooks JC (1988) Auditory mechanisms underlying a neural code for space in the cat's superior colliculus. In: Auditory function: neurobiological bases of hearing (Edelman GM, Gall WE, Cowan WM, eds), pp 431-455. New York: Wiley.

Mills AW (1958) On the minimum audible angle. J Acoust Soc Am 30:237-246.

Moore MJ, Caspary DM (1983) Strychnine blocks binaural inhibition in lateral superior olivary neurons. J Neurosci 3:237-247.

Morest DK (1968) The collateral system of the medial nucleus of the trapezoid body of the cat, its neuronal architecture and relation to the olivo-cochlear bundle. Brain Res 9:288-311.

Nelson PG, Erulkar SD (1963) Synaptic mechanisms of excitation and inhibition in the central auditory pathway. J Neurophysiol 26:908923.

Nuetzel JM, Hafter ER (1981) Lateralization of complex waveforms: spectral effects. J Acoust Soc Am 69:1112-1118. 
Ostapoff EM, Morest DK (1989) A degenerative disorder of the central auditory system of the gerbil. Hearing Res 37:141-162.

Ozdamar O, Dallos P (1978) Synchronous responses of the primary auditory fibers to the onset of tone burst and their relation to compound action potentials. Brain Res 155:169-175.

Pollak G (1988) Time is traded for intensity in the bats auditory system. Hearing Res 36:107-124.

Precht W, Baker R (1972) Synaptic organization of the vestibulotrochlear pathway. Exp Brain Res 14:158-184.

Rasmussen GL (1946) The olivary peduncle and other fiber projections of the superior olivary complex. J Comp Neurol 84:141-219.

Rayleigh Lord JWS (1945) The theory of sound, Vol 2 (2d ed). New York: Dover.

Redfern PA (1970) Neuromuscular transmission in newborn rats. J Physiol (Lond) 209:701-709.

Rose JE, Gross NB, Geisler CD, Hind JE (1966) Some neural mechanisms in the inferior colliculus of the cat which may be relevant to localization of a sound source. J Neurophysiol 29:288-314.

Ryan AF (1976) Hearing sensitivity of the mongolian gerbil, Meriones unguiculatus. J Acoust Soc Am 59:1222-1226.

Ryan AF, Woolf NK, Sharp FR (1982) Tonotopic organization in the central auditory pathway of the Mongolian gerbil: a 2-deoxyglucose study. J Comp Neurol 207:369-380.

Sanes DH, Rubel EW (1988) The ontogeny of inhibition and excitation in the gerbil lateral superior olive. J Neurosci 8:682-700.

Sanes DH, Geary WA, Wooten GF, Rubel EW (1987) Quantitative distribution of the glycine receptor in the auditory brain stem of the gerbil. J Neurosci 7:3793-3802.

Sanes DH, Merickel M, Rubel EW (1989) Evidence for an alteration of the tonotopic map in the gerbil cochlea during development. $\mathbf{J}$ Comp Neurol 279:436-444.

Semple MN, Kitzes LM (1985) Single-unit responses in the inferior colliculus: different consequences of contralateral and ipsilateral stimulation. J Neurophysiol 53:1483-1498.

Semple MN, Kitzes LM (1987) Binaural processing of sound pressure level in the inferior colliculus. J Neurophysiol 57:1130-1147.

Smith RL (1977) Short-term adaptation in single auditory nerve fibers: some poststimulatory effects. J Neurophysiol 40:1098-1 112

Smith RL (1979) Adaptation, saturation, and physiological masking in single auditory-nerve fibers. J Acoust Soc Am 65:166-178.

Spangler KM, Wart WB, Henkel CK (1985) The projections of principal cells of the medial nucleus of the trapezoid body in the cat. J Comp Neurol 238:249-262.

Spencer RF, Wenthold RJ, Baker R (1989) Evidence for glycine as an inhibitory neurotransmitter of vestibular, reticular, and prepositus hypoglossi neurons that project to the cat abducens nucleus. J Neurosci 9:2718-2736.
Suga N (1984) The extent to which biosonar information is represented in the bat auditory cortex. In: Dynamic aspects of neocortical function (Edelman GM, Gall WE, Cowan WM, eds), pp 315-373. New York: Wiley.

Tobias JV, Zerlin S (1959) Lateralization thresholds as a function of stimulus duration. J Acoust Soc Am 31:1591-1594.

Tolbert LP, Morest DK, Yurgelun-Todd DA (1982) The neuronal architecture of the anteroventral cochlear nucleus of the cat in the region of the cochlear nerve root: horseradish peroxidase labelling of identified cell types. Neuroscience 7:3031-3052.

Tsuchitani C (1988a) The inhibition of cat lateral superior olive unit excitatory responses to binaural tone bursts. I. The transient chopper response. J Neurophysiol 59:164-183.

Tsuchitani C (1988b) The inhibition of cat lateral superior olive unit excitatory responses to hinaural tone hursts. II. The sustained discharges. J Neurophysiol 59:184-211.

Warr WB (1982) Parallel ascending pathways from the cochlear nucleus: neuroanatomical evidence of functional specialization. In: Contributions to sensory physiology, Vol 7 (Neff WD, ed), pp 1-38. New York: Academic.

Wenstrup JJ, Ross LS, Pollak GD (1986) Binaural response organization within a frequency-band representation of the inferior colliculus: implications for sound localization. J Neurosci 6:962-973.

Wenthold RJ, Altschuler RA (1987) Immunocytochemical characterization of glycine and glycine receptors. J Mind Behav 8:491-501.

Woolf NK, Ryan AF (1984) The development of auditory function in the cochlea of the mongolian gerbil. Hearing Res 13:277-283.

Woolf NK, Ryan AF (1985) Ontogeny of neural discharge patterns in the ventral cochlear nucleus of the mongolian gerbil. Dev Brain Res 17:131-147.

Yin TCT, Kuwada S (1984) Neuronal mechanisms of binaural interaction. In: Dynamic aspects of neocortical function (Edelman GM, Gall WE, Cowan WM, eds), pp 263-313. New York: Wiley.

Yin TCT, Kuwada S, Sujaku Y (1984) Interaural time sensitivity of high-frequency neurons in the inferior colliculus. J Acoust Soc Am 76:1401-1410.

Yin TCT, Hirsch JA, Chan JCK (1985) Responses in the cat's superior colliculus to acoustic stimuli. II. A model of interaural intensity sensitivity. J Neurophysiol 53:746-758.

Yost WA (1976) Lateralization of repeated filtered transients. J Acoust Soc Am 60:178-181.

Zook JM, DiCaprio RA (1988) Intracellular labeling of afferents to the lateral superior olive in the bat, Eptesicus fuscus. Hearing Res 34: 141-148. 